\title{
Prevalence of symptoms of sleep apnoea syndrome in Burkina Faso
} \author{
R Nacanabo, ${ }^{3} \mathrm{MD}$; A Tiendrebeogo, ${ }^{1} \mathrm{MD}$; G Badoum, ${ }^{1} \mathrm{MD}$; M Ouédraogo, ${ }^{1} \mathrm{MD}$ \\ ${ }^{1}$ Department of Pulmonology, University Hospital Yalgado Ouédraogo, Ouagadougou, Burkina Faso \\ ${ }^{2}$ Department of Pulmonology, University Hospital Sylvanus Olympio, Lomé, Togo \\ ${ }^{3}$ Department of Pulmonology, Regional Hospital of Ouahigouya, Burkina Faso
}

G Ouédraogo, ${ }^{1} \mathrm{MD}$; A R Ouédraogo, ${ }^{1} \mathrm{MD}$; A S Adambounou, ${ }^{2} \mathrm{MD}$; K Boncoungou, ${ }^{1} \mathrm{MD} ; \mathrm{S} \mathrm{Maiga},{ }^{1} \mathrm{MD} ; \mathrm{R} \mathrm{Koalga},{ }^{1} \mathrm{MD}$;

Corresponding author: A R Ouédraogo (oarisgou@yahoo.fr)

\begin{abstract}
Introduction. Sleep apnoea syndrome (SAS) is a frequent and underdiagnosed pathology. Epidemiological studies in sub-Saharan Africa are few. Our study aimed to determine the prevalence of SAS symptoms in an adult population in Burkina Faso.

Method. A cross-sectional study whose data collection took place at the Yalgado Ouédraogo Teaching Hospital, from 1 September to 31 October 2014. We randomly enrolled all subjects aged at least 25 accompanying an outpatient $t$ the time of a visit. A strong suspicion of SAS was established for every combination of ordinary snoring with excessive daytime sleepiness and/or sleep apnoea.

Results. The study included 311 subjects - 181 men and 130 women. The mean (standard deviation (SD)) age was 31.84 (8.25) years and the average (SD) BMI was $23.14(3.67) \mathrm{kg} / \mathrm{m}^{2}$. The prevalence of excessive daytime sleepiness, snoring and sleep apnoea was $4.5 \%, 26 \%$ and $9.6 \%$, respectively. A strong suspicion of SAS was found in $9.6 \%$ of respondents and the risk factors associated with this strong suspicion were BMI $\geq 25 \mathrm{~kg} / \mathrm{m}^{2}$ (odds ratio (OR) $2.7 ; p=0.012$ ), and poor-quality sleep (OR $3.7 ; p<0.001$ ).

Conclusion. A significant proportion of our sample had symptoms suggestive of SAS. Testing with either respiratory polygraphy or polysomnography should be proposed to the presumptive cases for early diagnosis and treatment.
\end{abstract}

Afr J Thoracic Crit Care Med 2019;25(2):38-41. DOI:10.7196/AJTCCM.2019.v25i2.006

Sleep apnoea syndrome (SAS) is a common pathology of the middleaged adult. ${ }^{[1]}$ It is under diagnosed because it is poorly understood by both the general population and healthcare workers. It is a serious condition, mainly because of its neurocardiovascular (hypertension, cardiovascular disease, stroke), metabolic (diabetes, dyslipidemia, metabolic syndrome) and socio-occupational complications (road accidents, decreased quality of life). ${ }^{[2-8]}$ In Western countries, it is classified as a public health problem, with the prevalence varying from $3 \%$ to $28 \%$ in the adult population. ${ }^{[1]}$ Differences in population as well as the inhomogeneity of the definitions and diagnostic methods used probably explain part of the dispersion of observed prevalences. ${ }^{[9]}$ The diagnosis of SAS is based on a night recording, with either polysomnography or respiration polygraphy. However, in many countries, testing capacities are insufficient or non-existent and the resulting lack of diagnosis leads to insufficient management. ${ }^{[9]}$ The epidemiological studies available in the literature concerning this condition, come mainly from Western countries. In French-speaking sub-Saharan Africa, where resources are limited, there has been limited research on SAS diagnosis and management. This study was initiated to determine the prevalence of the main symptoms of SAS in the general population of Burkina Faso.

\section{Methods}

Framework and type of study

We conducted a descriptive and analytical cross-sectional study that took place at the Yalgado Ouédraogo University Hospital Center (CHU-YO), a reference centre in Burkina Faso. CHU-YO is located in Ouagadougou, the political and administrative capital of Burkina
Faso. The population of Burkina Faso was estimated at 19034397 inhabitants in 2016, with 2637303 inhabitants in Ouagadougou. ${ }^{[10]}$

\section{Study population}

The study targeted caregivers of outpatients in CHU-YO's Departments of Medicine and Surgery. This study randomly included all men and women aged 25 and over, who gave their informed consent. People working night shifts were excluded.

\section{Data collection}

The data were collected from 1September 2014 to 31 October 2014. An anonymous survey sheet collected the sociodemographic characteristics, the main symptoms of the SAS, the sleep habits as well as the significant medical histories. The Epworth scale was used to evaluate daytime sleepiness and the Pichot scale was used for fatigue. The questionnaire was administered as a one-on-one interview and explained in the local language for patients who did not speak French. The measurement of anthropometric parameters was done by an intern ( 7 th year medicine). Table 1 shows the operational definitions.

\section{Statistical analysis}

Data were analysed using Epi Info 7.2 statistics software (CDC, USA). Pearson's Gross $\chi^{2}$ test or Fischer's exact test was used to compare categorical variables when necessary. Mean values were presented with the standard deviation as the dispersion index. Associations between variables were considered statistically significant at the 0.05 probability threshold. 
Table 1. Operational definitions

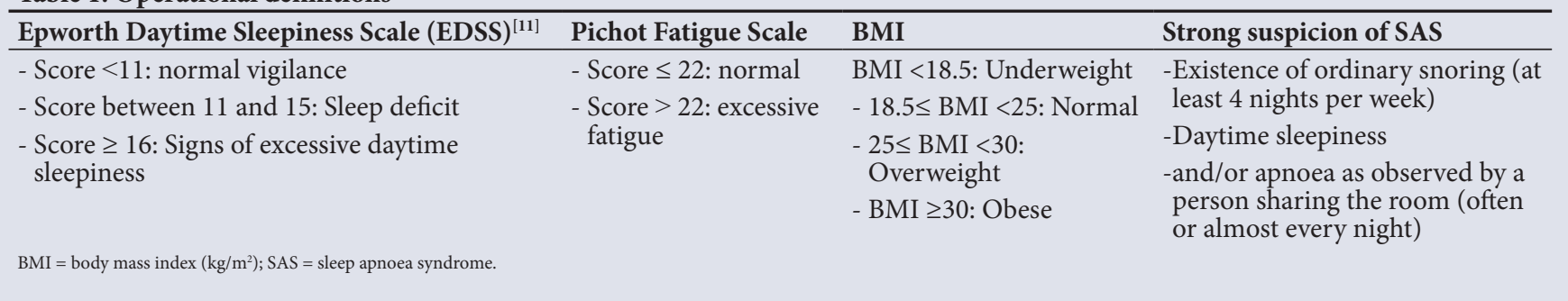

\section{Results}

\section{Sociodemographic characteristics and medical history}

The study involved 311 subjects whose characteristics are presented in Table 2 . The population was predominantly male (58.2\%) with a sex ratio of 1.43. The average (standard deviation (SD)) age of the subjects surveyed was 31.84 (8.25) years, with extremes of 25 and 70 years. More than half of them (59.2\%) had a higher education level and 53.7\% had a professional activity. The average (SD) body mass index (BMI) was $23.14(3.67) \mathrm{kg} / \mathrm{m}^{2}$, with extremes of 14.37 and $37.18 \mathrm{~kg} / \mathrm{m}^{2}$.

A history of hypertension was found in $3.8 \%$ and $14.5 \%$ consumed alcohol, while $6.4 \%$ were smokers. Of our respondents, $4.2 \%$ had had a non-sleep-related motor vehicle accident while driving. However, $5.1 \%$ were drowsy behind the wheel.

\section{Symptoms of SAS}

Among our respondents, $17.7 \%$ felt that the duration of their sleep was not sufficient. On the Epworth scale, $30.5 \%$ of the subjects surveyed had a sleep deficit (EDSS score between 11 and 15) and $4.5 \%$ had excessive daytime sleepiness (EDSS score $\geq 16$ ). The Pichot scale showed that $0.3 \%$ of our patients had excessive fatigue. Almost a quarter of our respondents (24.8\%) usually snored. The existence of respiratory pause during sleep was found in $9.6 \%$ of our investigations. Nocturia was greater than twice per night in $11.9 \%$ of subjects. The prevalence of high suspicion of SAS was 9.6\%. Subjects with high suspicion of SAS were older, had a higher mean BMI than the rest of the population, consumed alcohol and had a nocturia of more than two episodes a night. Factors associated with high suspicion of SAS are summarised in Table 3 .

\section{Discussion}

Sleep disorders are increasingly recognised as a real public health problem. ${ }^{[1]}$ Epidemiological studies of these conditions in the literature are mainly from Western countries. ${ }^{[12]}$ The management of SAS is recent in Burkina Faso, and it was necessary to initiate this study to determine the prevalence of the main symptoms of SAS in the general population of Ouagadougou. The average age of the surveyed subjects was 31.84 years, which is representative of the general young adult population of Burkina Faso. The present study had a prevalence of $9.6 \%$ of a strong suspicion of SAS. Studies in France and Morocco reported similar prevalence rates of $8.5 \%$ and $9.5 \%$, respectively. ${ }^{[9,12]}$ In the literature, the prevalence of SAS in the adult population varies between $3 \%$ and $28 \%{ }^{[1]}$ The differences in population and the inhomogeneity of definitions and diagnostic methods used probably explain some of the dispersion of observed prevalences. The diagnosis of SAS is based on a night recording, with either polysomnography or ventilation polygraphy. These
Table 2. Sociodemographic characteristics and medical history

\begin{tabular}{ll}
\hline Variables & Frequency, $\boldsymbol{n}$ (\%) \\
\hline Age group (years) & $170(54.7)$ \\
$<30$ & $99(31.8)$ \\
$30-39$ & $24(7.7)$ \\
$40-49$ & $13(4.2)$ \\
$50-59$ & $5(1.6)$ \\
$\geq 60$ & \\
Gender & $181(58.2)$ \\
Male & $130(41.8)$ \\
Female & \\
Level of education & $184(59.2)$ \\
College & $73(23.5)$ \\
High school & $35(11.2)$ \\
Primary school & $19(6.1)$ \\
No formal school education & \\
Profession & $118(37.9)$ \\
Pupils/students & $100(32.2)$ \\
Functionary & $45(14.4)$ \\
Informal sector & $22(7.1)$ \\
Merchants & $21(6.8)$ \\
Housewives & $5(1.6)$ \\
Retired & $12(3.8)$ \\
Body mass index & $231(74.3)$ \\
Underweight & $52(16.7)$ \\
Normal & $16(5.2)$ \\
Overweight & \\
Obesity & $45(14.5)$ \\
Past medical history & $20(6.4)$ \\
Alcohol & $12(3.8)$ \\
Tobacco & $9(2.9)$ \\
Depresstension & $8.6)$ \\
Asthma & \\
Diabetes & \\
&
\end{tabular}

diagnostic confirmation tools are necessary in our context where resources are limited. The country has only two facilities (one in the CHU-YO pulmonology department and the other in a private clinic) to diagnose sleep-related respiratory disorders. In these structures, the diagnosis is made using respiratory polygraphy. The testing capacities are therefore insufficient with regard to the prevalence of symptoms of SAS. It is hence necessary to set up sleep laboratories to ensure adequate care. 
Table 3. Factors associated with a high suspicion of SAS

\begin{tabular}{|c|c|c|c|c|c|}
\hline \multirow[b]{2}{*}{ Variables } & & \multicolumn{2}{|c|}{ High suspicion of SAS } & \multirow[b]{2}{*}{ OR (95\% CI) } & \multirow[b]{2}{*}{$p$-value } \\
\hline & & Yes, $n(\%)$ & No, $n(\%)$ & & \\
\hline \multirow[t]{2}{*}{ Gender } & Male & $19(10.4)$ & $164(89.6)$ & $1.2(0.6-2.7)$ & 0.60 \\
\hline & Female & $28(63.6)$ & $16(36.4)$ & & \\
\hline \multirow[t]{2}{*}{ Age (years) } & $\geq 45$ & $11(39.3)$ & $17(60.7)$ & $9(3.7-21.9)$ & 0.00 \\
\hline & $<45$ & $27(6.7)$ & $264(93.3)$ & & \\
\hline \multirow[t]{2}{*}{ BMI $\left(\mathrm{kg} / \mathrm{m}^{2}\right)$} & $\geq 25$ & $12(17.6)$ & $56(82.4)$ & $2.7(1.2-5.9)$ & 0.012 \\
\hline & $<25$ & $18(7.4)$ & $225(92.6)$ & & \\
\hline \multirow[t]{2}{*}{ Sufficient sleep } & No & $12(21.8)$ & $43(78.2)$ & $3.7(1.6-8.2)$ & 0.00 \\
\hline & Yes & $18(7.0)$ & $238(93)$ & & \\
\hline \multirow[t]{2}{*}{ History of hypertension } & Yes & $2(18.2)$ & $9(81.8)$ & $2.2(0.3-9.6)$ & 0.33 \\
\hline & No & $28(9.3)$ & $272(90.7)$ & & \\
\hline \multirow[t]{2}{*}{ Tobacco } & Yes & $1(5)$ & $19(95)$ & $0.5(0.1-2.8)$ & 0.47 \\
\hline & No & $29(10)$ & $262(90)$ & & \\
\hline \multirow[t]{2}{*}{ Alcohol } & Yes & $6(30)$ & $14(70)$ & $4.7(1.5-13.3)$ & 0.001 \\
\hline & No & $24(8.3)$ & $267(91.7)$ & & \\
\hline \multirow[t]{2}{*}{ Daytime sleepiness } & Yes & $14(100)$ & $0(0)$ & - & - \\
\hline & No & $16(5.4)$ & $281(94.6)$ & & \\
\hline \multirow[t]{2}{*}{ Snoring } & Yes & $18(23.4)$ & $59(76.6)$ & $5.6(2.8-12.6)$ & 0.000 \\
\hline & No & $12(5.1)$ & $222(94.9)$ & & \\
\hline \multirow[t]{2}{*}{ Respiratory pauses during sleep } & Yes & $15(50)$ & $15(50)$ & $17.4(7.2-43.1)$ & 0.000 \\
\hline & No & $15(5.3)$ & $266(94.7)$ & & \\
\hline \multirow[t]{2}{*}{ Pichot Scale } & $>22$ & $1(100)$ & $0(0)$ & - & - \\
\hline & $\leq 22$ & $29(9.4)$ & $281(91.6)$ & & \\
\hline \multirow[t]{2}{*}{ Nocturia } & $>22$ & $9(20.9)$ & $24(79.1)$ & $3.1(1.3-7.3)$ & 0.007 \\
\hline & $\leq 22$ & $21(7.8)$ & $247(92.2)$ & & \\
\hline
\end{tabular}

In our study, strong suspicion of SAS was noted in 19 men and 11 women. SAS is 2 to 3 times more common in men than in women in the main cohorts, including the Wisconsin Sleep Cohort Study (WSCS), Southern Pennsylvania Cohort (SPC) and Victoria-Gasteiz Spain Cohort (VGSC). ${ }^{[13-15]}$ These studies indicate that the prevalence of SAS almost linearly increases among adults up to age 65, independently of other risk factors. As a result, these studies have confirmed the increase in the prevalence of SAS in overweight individuals. ${ }^{[13-15]}$ In our study, subjects with high suspicion of SAS were older, and had a higher mean BMI than the rest of the population.

We defined the association of ordinary snoring with daytime sleepiness and/or frequent apnoeas observed by a room sharer as 'strong suspicion of sleep apnoea syndrome'. Indeed, snoring is an almost constant sign of SAS and it has been suggested that the diagnosis of SAS was most often made after a long history of snoring which became irregular and interspersed with apnoea. ${ }^{[16]}$ However, snoring does not necessarily mean SAOS. ${ }^{[17]}$ Snoring is very common in the general population; its prevalence increases in both sexes after age 35 . It has been recognised for about four decades that $60 \%$ of men and $40 \%$ of middle-aged women ( $40-60$ years) are habitual snorers. ${ }^{[16]}$ In our study, $24.8 \%$ of subjects usually snored. A prevarication bias commonly encountered in this type of study may explain the low proportion of snorers in our study.

The existence of excessive daytime sleepiness is also one of the major clinical criteria for diagnosing SAS. ${ }^{[18]}$ Here, we report $4.5 \%$ of subjects with excessive daytime sleepiness. Apnoeic subjects have nocturnal micro-awakenings that cause fragmentation and disorganisation of sleep. The quality of sleep is impaired because it becomes superficial and non-recuperative. This sleep debt is indirectly paid for by daytime sleepiness. ${ }^{[17]}$

Finally, the apnoeas documented in the literature are often a reason for consultation for unknown SAS carriers. The existence of respiratory pause during sleep was found in $9.6 \%$ of our respondents. These apnoeas are responsible for desaturations with sympathetic hyperactivity, excessive production of oxidants and exaggerated variations in intra-thoracic pressure at the origin of cardiovascular and metabolic disorders. ${ }^{[19]}$

However, our study did not aim to diagnose SAS by substituting for direct measurements of respiratory abnormalities during sleep. Indeed, none of the usual symptoms of SAS is specific enough to rule in the diagnosis. ${ }^{[20]}$ The combination of several symptoms, while improving the presumption, is also insufficient ${ }^{[21]}$ to establish the diagnosis of SAS. This study is certainly a first step on the estimated prevalence of clinical symptoms suggestive of SAS in the Burkinabe population.

\section{Conclusion}

Our study showed that the prevalence of the usual symptoms of SAS is high in a country where the management of sleep-disordered breathing is still in its early days. The prevalence of high suspicion 
of SAS was $9.6 \%$. Respiratory polygraphic and polysomnographic testing should be offered to presumptive cases for early diagnosis and treatment. A prevalence survey of SAS should be conducted nationally to assess the true extent of the problem in Burkina Faso.

Acknowledgements. The authors thank the Espace Francophone de Pneumologie (EFP), the French-speaking African Society of Pulmonology (SAPLF), the Burkinabe Society of Pulmonology (SOBUP) and the University of SFAX in Tunisia for their help in practical training.

Author contributions. ARO conceived of the study, and participated in its design, performance, statistics, coordination, drafting and revising of the manuscript. GO and ASA participated in its design, coordination, drafting and revising of the manuscript. KB and SM participated in its design, statistics, and revising of the manuscript. KR, RN and AT participated in its design, statistics, performance, data collection, drafting and revising of the manuscript. GB and MO conceived of the study, and participated in its design, coordination and revising of the manuscript. All authors read and approved the final manuscript.

Funding. None.

Conflicts of interest. None.

1. Young T, Peppard PE, Gottlieb DJ. Epidemiology of obstructive sleep apnoea. A population health perspective. Am J Respir Crit Care Med 2002;165:1217-1239. https://doi.org/10.1164/rccm.2109080

2. Nieto FJ, Young TB, Lind BK. Association of sleep disordered breathing, sleep apnoea and hypertension in a large community-based study. JAMA 2000;283:1829-1836. http://doi:10.1001/jama.283.14.1829

3. Peppard PE, Young T, Palta M, Skatrud J. Prospective study of the association between sleep-disordered breathing and hypertension. N Engl J Med 2000;342:1378-1384. http://DOI: 10.1056/NEJM200005113421901

4. Mooe T, Rabben T, Wiklund U, Franklin KA, Eriksson P. Sleep-disordered breathing in men with coronary artery disease. Chest 1996;109:659-663. https://doi.org/10.1378/ chest.109.3.659

5. Shahar E, Whitney CW, Redline S. Sleep-disordered breathing and cardio-vascular disease. Am J Respir Crit Care Med 2001; 163 : 19-25. https://doi.org/10.1164/ ajrccm.163.1.2001008

6. Meslier N, Gagnadoux F, Girault P. Impaired glucose-insulin metabolism in men with obstructive sleep apnoea syndrome. Eur Respir J 2003;22:156-160. https://doi.org/10.1183/09031936.03.00089902
7. Teran-Santos J, Jimenez-Gomez A, Cordero-Guevara J. The association between sleep apnoea and the risk of traffic accidents. Cooperative Group Burgos-Santander. N Engl J Med 1999;340:847-851. https://doi.org/10.1056/NEJM199903183401104

8. Lindberg E, Carter N, Gislason T, Janson C. Role of snoring and daytime sleepiness in occupational accidents. Am J Respir Crit Care Med. 2001;164:2031-2035. https:// doi.org/10.1164/ajrccm.164.11.2102028

9. Meslier N, Vol S, Balkau B. Prévalence des symptômes du syndrome d'apnées du sommeil. Étude dans une population française d'âge moyen. Rev Mal Respir 2007;24:305-313. http://dx.doi.org/10.1016/S0761-8425(07)91062-1

10. Institut National de la Statistique et de la Démographie. Annuaire Statistique 2016. Burkina Faso; 2017:379.

11. Johns MW. A new method for measuring daytime sleepiness; the Epworth Sleepiness Scale. Sleep 1991;14:540-545. https://doi.org/10.1093/sleep/14.6.540

12. Jniene A, El Ftouh M, El Fassy Fihry MT. Study of the prevalence of sleep apnoea syndrome's symptoms in a Moroccan population. Tuberk Toraks 2012; 60(2):108-113. https://doi.org/10.5578/tt.3156

13. Young T, Palta M, Dempsey J, Skatrud J, Weber S, Badr S. The occurrence of sleepdisordered breathing among middle-aged adults. N Engl J Med 1993;328:1230-1235 https://doi.org/10.1056/NEJM199304293281704

14. Bixler EO, Vgontzas AN, Ten Have T, et al. Effects of age on sleep apnoea in men: I. Prevalence and severity. Am J Respir Crit Care Med 1998;157(1):144-148. https://doi. org/10.1164/ajrccm.157.1.9706079

15. Durán J, Esnaola R, Rubio R, et al. Obstructive sleep apnoea-hypopnoea and related clinical features in a population-based sample subjects aged 30 to $70 \mathrm{yr}$. Am J Respir Crit Care Med 2001;163(3):685-689. https://doi.org/10.1164/ajrccm.163.3.2005065

16. Lugaresi E, Mondini S, Zucconi M, Montagna P, Cirignotta F. Staging of heavy snorers disease: A proposal. Bull Eur Physiopathol Respir 1983;19:590-594.

17. Guilleminault C, Stoohs R, Clerk A, Cetel M, Maistros P. A cause of excessive daytime sleepiness: The upper airway resistance syndrome. Chest 1993;104(3):781-787. https:// doi.org/10.1378/chest.104.3.781

18. American Academy of Sleep Medicine Task Force. Sleep-breathing disorders in adults: Recommendations for syndrome definition and measurement techniques in clinical research. Sleep 1999;22(5):667-689. https://doi.org/10.1093/sleep/22.5.667

19. Roisman G, Ibrahima Escourroua P. Pourquoi et comment diagnostiquer les troubles respiratoires du sommeil? Revue de Pneumologie Clinique 2009;65:203-213. https:// doi.org/10.1016/j.pneumo.2009.07.003

20. Flemons WW, Whitelaw WA, Brant R, Remmers JE. Likelihood ratios for a sleep apnoea clinical prediction rule. Am J Respir Crit Care Med 1994;150:1279-1285. https://doi.org/10.1164/ajrccm.150.5.7952553

21. Kapuniai LE, Andrew DJ, Crowell DH, Pearce JW. Identifying sleep apnoea from selfreports. Sleep 1988;11:430-436. https://doi.org/10.1093/sleep/11.5.430

Accepted 29 May 2019 